\title{
Fixed point results for single and set-valued $\alpha-\eta-\psi$-contractive mappings
}

\author{
Nawab Hussain ${ }^{1}$, Peyman Salimi ${ }^{2}$ and Abdul Latif ${ }^{*}$
}

Dedicated to Professor Wataru Takahashi on the occasion of his seventieth birthday

"Correspondence: alatif@kau.edu.sa

'Department of Mathematics, King Abdulaziz University, P.O. Box 80203 Jeddah, 21589, Saudi Arabia Full list of author information is available at the end of the article

\begin{abstract}
Samet et al. (Nonlinear Anal. 75:2154-2165, 2012) introduced $\alpha$ - $\psi$-contractive mappings and proved some fixed point results for these mappings. More recently Salimi et al. (Fixed Point Theory Appl. 2013:151, 2013) modified the notion of $\alpha-\psi$-contractive mappings and established certain fixed point theorems. Here, we continue to utilize these modified notions for single-valued Geraghty and Meir-Keeler-type contractions, as well as multi-valued contractive mappings. Presented theorems provide main results of Hussain et al. (J. Inequal. Appl. 2013:114, 2013), Karapinar et al. (Fixed Point Theory Appl. 2013:34, 2013) and Asl et al. (Fixed Point Theory Appl. 2012:212, 2012) as corollaries. Moreover, some examples are given here to illustrate the usability of the obtained results.
\end{abstract}

MSC: $46 \mathrm{~N} 40 ; 47 \mathrm{H} 10 ; 54 \mathrm{H} 25 ; 46 \mathrm{~T} 99$

Keywords: modified Meir-Keeler-type contractions; triangular $\alpha$-admissible map; $\alpha-\eta$ - $\psi$-contractive map; metric space

\section{Introduction and preliminaries}

In metric fixed point theory, the contractive conditions on underlying functions play an important role for finding solution of fixed point problems. Banach contraction principle is a remarkable result in metric fixed point theory. Over the years, it has been generalized in different directions by several mathematicians (see [1-21]). In 2012, Samet et al. [15] introduced the concepts of $\alpha-\psi$-contractive and $\alpha$-admissible mappings and established various fixed point theorems for such mappings in complete metric spaces. Afterwards, Karapinar and Samet [13] generalized these notions to obtain fixed point results. More recently, Salimi et al. [14] modified the notions of $\alpha$ - $\psi$-contractive and $\alpha$-admissible mappings and established fixed point theorems, which are proper generalizations of the recent results in $[13,15]$. Here, we continue to utilize these modified notions for singlevalued Geraghty and Meir-Keeler-type contractions, as well as multivalued contractive mappings. Presented theorems provide main results of Hussain et al. [9], Karapinar et al. [11] and Asl et al. [12] as corollaries. Moreover, some examples are given here to illustrate the usability of the obtained results.

Denote with $\Psi$ the family of nondecreasing functions $\psi:[0,+\infty) \rightarrow[0,+\infty)$ such that $\sum_{n=1}^{\infty} \psi^{n}(t)<+\infty$ for all $t>0$, where $\psi^{n}$ is the $n$th iterate of $\psi$.

The following lemma is obvious.

(0) 2013 Hussain et al: licensee Springer. This is an Open Access article distributed under the terms of the Creative Commons Attribution License (http://creativecommons.org/licenses/by/2.0), which permits unrestricted use, distribution, and reproduction in any medium, provided the original work is properly cited. 
Lemma 1.1 If $\psi \in \Psi$, then $\psi(t)<t$ for all $t>0$.

Samet et al. [15] defined the notion of $\alpha$-admissible mappings as follows.

Definition 1.1 Let $T$ be a self-mapping on $X$, and let $\alpha: X \times X \rightarrow[0,+\infty)$ be a function. We say that $T$ is an $\alpha$-admissible mapping if

$$
x, y \in X, \quad \alpha(x, y) \geq 1 \quad \Longrightarrow \quad \alpha(T x, T y) \geq 1 .
$$

Theorem 1.1 [15] Let $(X, d)$ be a complete metric space, and let $T$ be an $\alpha$-admissible mapping. Assume that

$$
\alpha(x, y) d(T x, T y) \leq \psi(d(x, y))
$$

for all $x, y \in X$, where $\psi \in \Psi$. Also, suppose that

(i) there exists $x_{0} \in X$ such that $\alpha\left(x_{0}, T x_{0}\right) \geq 1$;

(ii) either $T$ is continuous or for any sequence $\left\{x_{n}\right\}$ in $X$ with $\alpha\left(x_{n}, x_{n+1}\right) \geq 1$ for all $n \in \mathbb{N} \cup\{0\}$ and $x_{n} \rightarrow x$ as $n \rightarrow+\infty$, we have $\alpha\left(x_{n}, x\right) \geq 1$ for all $n \in \mathbb{N} \cup\{0\}$.

Then $T$ has a fixed point.

Very recently Salimi et al. [14] modified the notions of $\alpha$-admissible and $\alpha$ - $\psi$-contractive mappings as follows.

Definition 1.2 [14] Let $T$ be a self-mapping on $X$, and let $\alpha, \eta: X \times X \rightarrow[0,+\infty)$ be two functions. We say that $T$ is an $\alpha$-admissible mapping with respect to $\eta$ if

$$
x, y \in X, \quad \alpha(x, y) \geq \eta(x, y) \quad \Longrightarrow \quad \alpha(T x, T y) \geq \eta(T x, T y) .
$$

Note that if we take $\eta(x, y)=1$, then this definition reduces to Definition 1.1. Also, if we take $\alpha(x, y)=1$, then we say that $T$ is $\eta$-subadmissible mapping.

The following result properly contains Theorem 1.1 and Theorems 2.3 and 2.4 of [13].

Theorem 1.2 [14] Let $(X, d)$ be a complete metric space, and let $T$ be an $\alpha$-admissible mapping with respect to $\eta$. Assume that

$$
x, y \in X, \quad \alpha(x, y) \geq \eta(x, y) \quad \Longrightarrow \quad d(T x, T y) \leq \psi(M(x, y)),
$$

where $\psi \in \Psi$ and

$$
M(x, y)=\max \left\{d(x, y), \frac{d(x, T x)+d(y, T y)}{2}, \frac{d(x, T y)+d(y, T x)}{2}\right\} .
$$

Also, suppose that the following assertions hold:

(i) there exists $x_{0} \in X$ such that $\alpha\left(x_{0}, T x_{0}\right) \geq \eta\left(x_{0}, T x_{0}\right)$;

(ii) either $T$ is continuous or for any sequence $\left\{x_{n}\right\}$ in $X$ with $\alpha\left(x_{n}, x_{n+1}\right) \geq \eta\left(x_{n}, x_{n+1}\right)$ for 
all $n \in \mathbb{N} \cup\{0\}$ and $x_{n} \rightarrow x$ as $n \rightarrow+\infty$, we have $\alpha\left(x_{n}, x\right) \geq \eta\left(x_{n}, x\right)$ for all $n \in \mathbb{N} \cup\{0\}$.

Then $T$ has a fixed point.

\section{Modified $\alpha-\eta$-Geraghty type contractions}

Our first main result of this section is concerning $\alpha-\eta$-Geraghty-type [4] contractions.

Theorem 2.1 Let $(X, d)$ be a complete metric space, and let $f: X \rightarrow X$ be an $\alpha$-admissible mapping with respect to $\eta$. Assume that there exists a function $\beta:[0, \infty) \rightarrow[0,1)$ such that for any bounded sequence $\left\{t_{n}\right\}$ of positive reals, $\beta\left(t_{n}\right) \rightarrow 1$ implies that $t_{n} \rightarrow 0$ and

$$
\begin{aligned}
x, y \in X, \quad \alpha(x, f x) \alpha(y, f y) & \geq \eta(x, f x) \eta(y, f y) \\
\Longrightarrow & d(f x, f y) \leq \beta(d(x, y)) \max \{d(x, y), \min \{d(x, f x), d(y, f y)\}\} .
\end{aligned}
$$

\section{Suppose that either}

(a) $f$ is continuous, or

(b) if $\left\{x_{n}\right\}$ is a sequence in $X$ such that $x_{n} \rightarrow x, \alpha\left(x_{n}, x_{n+1}\right) \geq \eta\left(x_{n}, x_{n+1}\right)$ for all $n$, then $\alpha(x, f x) \geq \eta(x, f x)$.

If there exists $x_{0} \in X$ such that $\alpha\left(x_{0}, f x_{0}\right) \geq \eta\left(x_{0}, f x_{0}\right)$, then $f$ has a fixed point.

Proof Let $x_{0} \in X$ such that $\alpha\left(x_{0}, f x_{0}\right) \geq \eta\left(x_{0}, f x_{0}\right)$. Define a sequence $\left\{x_{n}\right\}$ in $X$ by $x_{n}=$ $f^{n} x_{0}=f x_{n-1}$ for all $n \in \mathbb{N}$. If $x_{n+1}=x_{n}$ for some $n \in \mathbb{N}$, then $x=x_{n}$ is a fixed point for $f$, and the result is proved. Hence, we suppose that $x_{n+1} \neq x_{n}$ for all $n \in \mathbb{N}$. Since $f$ is an $\alpha$-admissible mapping with respect to $\eta$ and $\alpha\left(x_{0}, f x_{0}\right) \geq \eta\left(x_{0}, f x_{0}\right)$, we deduce that $\alpha\left(x_{1}, x_{2}\right)=\alpha\left(f x_{0}, f^{2} x_{0}\right) \geq \eta\left(f x_{0}, f^{2} x_{0}\right)=\eta\left(x_{1}, x_{2}\right)$. By continuing this process, we get $\alpha\left(x_{n}, f x_{n}\right) \geq \eta\left(x_{n}, f x_{n}\right)$ for all $n \in \mathbb{N} \cup\{0\}$. Then,

$$
\alpha\left(x_{n-1}, f x_{n-1}\right) \alpha\left(x_{n}, f x_{n}\right) \geq \eta\left(x_{n-1}, f x_{n-1}\right) \eta\left(x_{n}, f x_{n}\right) .
$$

Now from (2.1), we have

$$
\begin{aligned}
d\left(x_{n}, x_{n+1}\right) & \leq \beta\left(d\left(x_{n-1}, x_{n}\right)\right) \max \left\{d\left(x_{n-1}, x_{n}\right), \min \left\{d\left(x_{n-1}, f x_{n-1}\right), d\left(x_{n}, f x_{n}\right)\right\}\right\} \\
& =\beta\left(d\left(x_{n-1}, x_{n}\right)\right) \max \left\{d\left(x_{n-1}, x_{n}\right), \min \left\{d\left(x_{n-1}, x_{n}\right), d\left(x_{n}, x_{n+1}\right)\right\}\right\} .
\end{aligned}
$$

Now, if $d\left(x_{n-1}, x_{n}\right)<d\left(x_{n}, x_{n+1}\right)$ for some $n \in \mathbb{N}$, then

$$
\max \left\{d\left(x_{n-1}, x_{n}\right), \min \left\{d\left(x_{n-1}, x_{n}\right), d\left(x_{n}, x_{n+1}\right)\right\}\right\}=d\left(x_{n-1}, x_{n}\right) .
$$

Also, if $d\left(x_{n}, x_{n+1}\right) \leq d\left(x_{n-1}, x_{n}\right)$ for some $n \in \mathbb{N}$, then

$$
\max \left\{d\left(x_{n-1}, x_{n}\right), \min \left\{d\left(x_{n-1}, x_{n}\right), d\left(x_{n}, x_{n+1}\right)\right\}\right\}=d\left(x_{n-1}, x_{n}\right) .
$$

That is, for all $n \in \mathbb{N}$, we have

$$
\max \left\{d\left(x_{n-1}, x_{n}\right), \min \left\{d\left(x_{n-1}, x_{n}\right), d\left(x_{n}, x_{n+1}\right)\right\}\right\}=d\left(x_{n-1}, x_{n}\right) .
$$


Hence,

$$
d\left(x_{n}, x_{n+1}\right) \leq \beta\left(d\left(x_{n-1}, x_{n}\right)\right) d\left(x_{n-1}, x_{n}\right)
$$

for all $n \in \mathbb{N}$, which implies that $d\left(x_{n}, x_{n+1}\right) \leq d\left(x_{n-1}, x_{n}\right)$. It follows that the sequence $\left\{d\left(x_{n}, x_{n+1}\right)\right\}$ is decreasing. Thus, there exists $d \in \mathbb{R}_{+}$such that $\lim _{n \rightarrow \infty} d\left(x_{n}, x_{n+1}\right)=d$. We shall prove that $d=0$. From (2.2), we have

$$
\frac{d\left(x_{n}, x_{n+1}\right)}{d\left(x_{n-1}, x_{n}\right)} \leq \beta\left(d\left(x_{n-1}, x_{n}\right)\right) \leq 1,
$$

which implies that $\lim _{n \rightarrow \infty} \beta\left(d\left(x_{n-1}, x_{n}\right)\right)=1$. Regarding the property of the function $\beta$, we conclude that

$$
\lim _{n \rightarrow \infty} d\left(x_{n}, x_{n+1}\right)=0
$$

Next, we shall prove that $\left\{x_{n}\right\}$ is a Cauchy sequence. Suppose, to the contrary, that $\left\{x_{n}\right\}$ is not a Cauchy sequence. Then there is $\varepsilon>0$ and sequences $\{m(k)\}$ and $\{n(k)\}$ such that for all positive integers $k$, we have

$$
n(k)>m(k)>k, \quad d\left(x_{n(k)}, x_{m(k)}\right) \geq \varepsilon \quad \text { and } \quad d\left(x_{n(k)}, x_{m(k)-1}\right)<\varepsilon .
$$

By the triangle inequality, we derive that

$$
\begin{aligned}
\varepsilon & \leq d\left(x_{n(k)}, x_{m(k)}\right) \leq d\left(x_{n(k)}, x_{m(k)-1}\right)+d\left(x_{m(k)-1}, x_{m(k)}\right) \\
& <\varepsilon+d\left(x_{m(k)-1}, x_{m(k)}\right)
\end{aligned}
$$

$k \in \mathbb{N}$. Taking the limit as $k \rightarrow+\infty$ in the inequality above, and regarding the limit in (2.3), we get

$$
\lim _{k \rightarrow+\infty} d\left(x_{n(k)}, x_{m(k)}\right)=\varepsilon
$$

Again, by the triangle inequality, we find that

$$
d\left(x_{n(k)}, x_{m(k)}\right) \leq d\left(x_{m(k)}, x_{m(k)+1}\right)+d\left(x_{m(k)+1}, x_{n(k)+1}\right)+d\left(x_{n(k)+1}, x_{n(k)}\right)
$$

and

$$
d\left(x_{n(k)+1}, x_{m(k)+1}\right) \leq d\left(x_{m(k)}, x_{m(k)+1}\right)+d\left(x_{m(k)}, x_{n(k)}\right)+d\left(x_{n(k)+1}, x_{n(k)}\right) .
$$

Taking the limit in inequality above as $k \rightarrow+\infty$, together with (2.3) and (2.4), we deduce that

$$
\lim _{k \rightarrow+\infty} d\left(x_{n(k)+1}, x_{m(k)+1}\right)=\varepsilon .
$$

Now, since

$$
\alpha\left(x_{n(k)}, f x_{n(k)}\right) \alpha\left(x_{m(k)}, f x_{m(k)}\right) \geq \eta\left(x_{n(k)}, f x_{n(k)}\right) \eta\left(x_{m(k)}, f x_{m(k)}\right),
$$


then from (2.1), (2.4) and (2.5), we have

$$
\begin{aligned}
& d\left(x_{n(k)+1}, x_{m(k)+1}\right) \\
& \quad \leq \beta\left(d\left(x_{n(k)}, x_{m(k)}\right)\right) \max \left\{d\left(x_{n(k)}, x_{m(k)}\right), \min \left\{d\left(x_{n(k)}, f x_{n(k)}\right), d\left(x_{m(k)}, f x_{m(k)}\right)\right\}\right\} \\
& \quad=\beta\left(d\left(x_{n(k)}, x_{m(k)}\right)\right) \max \left\{d\left(x_{n(k)}, x_{m(k)}\right), \min \left\{d\left(x_{n(k)}, x_{n(k)+1}\right), d\left(x_{m(k)}, x_{m(k)+1}\right)\right\}\right\} .
\end{aligned}
$$

Hence,

$$
\frac{d\left(x_{n(k)+1}, x_{m(k)+1}\right)}{\max \left\{d\left(x_{n(k)}, x_{m(k)}\right), \min \left\{d\left(x_{n(k)}, x_{n(k)+1}\right), d\left(x_{m(k)}, x_{m(k)+1}\right)\right\}\right\}} \leq \beta\left(d\left(x_{n(k)}, x_{m(k)}\right)\right) \leq 1 .
$$

Letting $k \rightarrow \infty$ in the inequality above, we get

$$
\lim _{n \rightarrow \infty} \beta\left(d\left(x_{n(k)}, x_{m(k)}\right)\right)=1
$$

That is, $\lim _{k \rightarrow \infty} d\left(x_{n(k)}, x_{m(k)}\right)=0$, which is a contradiction. Hence $\left\{x_{n}\right\}$ is a Cauchy sequence. Since $X$ is complete, then there is $z \in X$ such that $x_{n} \rightarrow z$. First, we suppose that $f$ is continuous. Since $f$ is continuous, then we have

$$
f z=\lim _{n \rightarrow \infty} f x_{n}=\lim _{n \rightarrow \infty} x_{n+1}=z .
$$

So $z$ is a fixed point of $f$. Next, we suppose that (b) holds. Then, $\alpha(z, f z) \geq \eta(z, f z)$, and so, $\alpha(z, f z) \alpha\left(x_{n}, f x_{n}\right) \geq \eta(z, f z) \eta\left(x_{n}, f x_{n}\right)$. Now by $(2.1)$, we have

$$
d\left(f z, x_{n+1}\right) \leq \beta\left(d\left(z, x_{n}\right)\right) \max \left\{d\left(z, x_{n}\right), \min \left\{d(z, f z), d\left(x_{n}, x_{n+1}\right)\right\}\right\},
$$

and hence

$$
\begin{aligned}
d(f z, z) & \leq d\left(f z, x_{n+1}\right)+d\left(z, x_{n+1}\right) \\
& \leq \beta\left(d\left(z, x_{n}\right)\right) \max \left\{d\left(z, x_{n}\right), \min \left\{d(z, f z), d\left(x_{n}, x_{n+1}\right)\right\}\right\}+d\left(z, x_{n+1}\right) .
\end{aligned}
$$

Letting $n \rightarrow \infty$ in the inequality above, we get $d(f z, z)=0$, that is, $z=f z$.

If in Theorem 2.1 we take, $\eta(x, y)=1$, then we have the following corollary.

Corollary 2.1 Let $(X, d)$ be a complete metric space, and let $f: X \rightarrow X$ be an $\alpha$-admissible mapping. Assume that there exists a function $\beta:[0, \infty) \rightarrow[0,1]$ such that for any bounded sequence $\left\{t_{n}\right\}$ of positive reals, $\beta\left(t_{n}\right) \rightarrow 1$ implies that $t_{n} \rightarrow 0$ and

$$
\begin{aligned}
& x, y \in X, \quad \alpha(x, f x) \alpha(y, f y) \geq 1 \\
& \Longrightarrow \quad d(f x, f y) \leq \beta(d(x, y)) \max \{d(x, y), \min \{d(x, f x), d(y, f y)\}\} .
\end{aligned}
$$

\section{Suppose that either}

(a) $f$ is continuous, or

(b) if $\left\{x_{n}\right\}$ is a sequence in $X$ such that $x_{n} \rightarrow x, \alpha\left(x_{n}, x_{n+1}\right) \geq 1$ for all $n$, then $\alpha(x, f x) \geq 1$.

If there exists $x_{0} \in X$ such that $\alpha\left(x_{0}, f x_{0}\right) \geq 1$, then $f$ has a fixed point. 
Corollary 2.2 Let $(X, d)$ be a complete metric space, and let $f: X \rightarrow X$ be an $\alpha$-admissible mapping. Assume that there exists a function $\beta:[0, \infty) \rightarrow[0,1]$ such that for any bounded sequence $\left\{t_{n}\right\}$ of positive reals, $\beta\left(t_{n}\right) \rightarrow 1$ implies that $t_{n} \rightarrow 0$ and

$$
(d(f x, f y)+\ell)^{\alpha(x, f x) \alpha(y, f y)} \leq \beta(d(x, y)) \max \{d(x, y), \min \{d(x, f x), d(y, f y)\}\}+\ell
$$

for all $x, y \in X$, where $\ell>0$. Suppose that either

(a) $f$ is continuous, or

(b) if $\left\{x_{n}\right\}$ is a sequence in $X$ such that $x_{n} \rightarrow x, \alpha\left(x_{n}, x_{n+1}\right) \geq 1$ for all $n$, then $\alpha(x, f x) \geq 1$. If there exists $x_{0} \in X$ such that $\alpha\left(x_{0}, f x_{0}\right) \geq 1$, then $f$ has a fixed point.

Corollary 2.3 Let $(X, d)$ be a complete metric space, and let $f: X \rightarrow X$ be an $\alpha$-admissible mapping. Assume that there exists a function $\beta:[0, \infty) \rightarrow[0,1]$ such that for any bounded sequence $\left\{t_{n}\right\}$ of positive reals, $\beta\left(t_{n}\right) \rightarrow 1$ implies that $t_{n} \rightarrow 0$ and

$$
(\alpha(x, f x) \alpha(y, f y)+1)^{d(f x, f y)} \leq 2^{\beta(d(x, y)) \max \{d(x, y), \min \{d(x, f x), d(y, f y)\}\}}
$$

for all $x, y \in X$. Suppose that either

(a) $f$ is continuous, or

(b) if $\left\{x_{n}\right\}$ is a sequence in $X$ such that $x_{n} \rightarrow x, \alpha\left(x_{n}, x_{n+1}\right) \geq 1$ for all $n$, then $\alpha(x, f x) \geq 1$. If there exists $x_{0} \in X$ such that $\alpha\left(x_{0}, f x_{0}\right) \geq 1$, then $f$ has a fixed point.

Corollary 2.4 Let $(X, d)$ be a metric space such that $(X, d)$ is complete and $f: X \rightarrow X$ be an $\alpha$-admissible mapping. Assume that there exists a function $\beta:[0, \infty) \rightarrow[0,1]$ such that for any bounded sequence $\left\{t_{n}\right\}$ of positive reals, $\beta\left(t_{n}\right) \rightarrow 1$ implies that $t_{n} \rightarrow 0$ and

$$
\alpha(x, f x) \alpha(y, f y) d(f x, f y) \leq \beta(d(x, y)) \max \{d(x, y), \min \{d(x, f x), d(y, f y)\}\}
$$

for all $x, y \in X$. Suppose that either

(a) $f$ is continuous, or

(b) if $\left\{x_{n}\right\}$ is a sequence in $X$ such that $x_{n} \rightarrow x, \alpha\left(x_{n}, f x_{n}\right) \geq 1$ for all $n$, then $\alpha(x, f x) \geq 1$.

If there exists $x_{0} \in X$ such that $\alpha\left(x_{0}, f x_{0}\right) \geq 1$, then $f$ has a fixed point.

Further, if in Theorem 2.1 we take $\alpha(x, y)=1$, then we have the following corollary.

Corollary 2.5 Let $(X, d)$ be a complete metric space, and let $f: X \rightarrow X$ be a $\eta$-subadmissible mapping. Assume that there exists a function $\beta:[0, \infty) \rightarrow[0,1]$ such that for any bounded sequence $\left\{t_{n}\right\}$ of positive reals, $\beta\left(t_{n}\right) \rightarrow 1$ implies that $t_{n} \rightarrow 0$ and

$$
\begin{aligned}
x, y \in X, \quad \eta(x, f x) \eta(y, f y) \leq 1 \\
\Longrightarrow \quad d(f x, f y) \leq \beta(d(x, y)) \max \{d(x, y), \min \{d(x, f x), d(y, f y)\}\} .
\end{aligned}
$$

Suppose that either

(a) $f$ is continuous, or

(b) if $\left\{x_{n}\right\}$ is a sequence in $X$ such that $x_{n} \rightarrow x, \eta\left(x_{n}, x_{n+1}\right) \leq 1$ for all $n$, then $\eta(x, f x) \leq 1$. If there exists $x_{0} \in X$ such that $\eta\left(x_{0}, f x_{0}\right) \leq 1$, then $f$ has a fixed point. 
Corollary 2.6 Let $(X, d)$ be a complete metric space, and let $f: X \rightarrow X$ be a $\eta$-subadmissible mapping. Assume that there exists a function $\beta:[0, \infty) \rightarrow[0,1]$ such that for any bounded sequence $\left\{t_{n}\right\}$ of positive reals, $\beta\left(t_{n}\right) \rightarrow 1$ implies that $t_{n} \rightarrow 0$ and

$$
d(f x, f y)+\ell \leq[\beta(d(x, y)) \max \{d(x, y), \min \{d(x, f x), d(y, f y)\}\}+\ell]^{\eta(x, f x) \eta(y, f y)}
$$

for all $x, y \in X$, where $\ell>0$. Suppose that either

(a) $f$ is continuous, or

(b) if $\left\{x_{n}\right\}$ is a sequence in $X$ such that $x_{n} \rightarrow x, \eta\left(x_{n}, x_{n+1}\right) \leq 1$ for all $n$, then $\eta(x, f x) \leq 1$.

If there exists $x_{0} \in X$ such that $\eta\left(x_{0}, f x_{0}\right) \leq 1$, then $f$ has a fixed point.

Corollary 2.7 Let $(X, d)$ be a complete metric space, and let $f: X \rightarrow X$ be a $\eta$-subadmissible mapping. Assume that there exists a function $\beta:[0, \infty) \rightarrow[0,1]$ such that for any bounded sequence $\left\{t_{n}\right\}$ of positive reals, $\beta\left(t_{n}\right) \rightarrow 1$ implies that $t_{n} \rightarrow 0$ and

$$
2^{d(f x, f y)} \leq(\eta(x, f x) \eta(y, f y)+1)^{\beta(d(x, y)) \max \{d(x, y), \min \{d(x, f x), d(y, f y)\}\}}
$$

for all $x, y \in X$. Suppose that either

(a) $f$ is continuous, or

(b) if $\left\{x_{n}\right\}$ is a sequence in $X$ such that $x_{n} \rightarrow x, \eta\left(x_{n}, x_{n+1}\right) \leq 1$ for all $n$, then $\eta(x, f x) \leq 1$.

If there exists $x_{0} \in X$ such that $\eta\left(x_{0}, f x_{0}\right) \leq 1$, then $f$ has a fixed point.

Corollary 2.8 Let $(X, d)$ be a metric space such that $(X, d)$ is complete, and let $f: X \rightarrow X$ be $\eta$-subadmissible mapping. Assume that there exists a function $\beta:[0, \infty) \rightarrow[0,1]$ such that for any bounded sequence $\left\{t_{n}\right\}$ of positive reals, $\beta\left(t_{n}\right) \rightarrow 1$ implies that $t_{n} \rightarrow 0$ and

$$
d(f x, f y) \leq \eta(x, f x) \eta(y, f y) \beta(d(x, y)) \max \{d(x, y), \min \{d(x, f x), d(y, f y)\}\}
$$

for all $x, y \in X$. Suppose that either

(a) $f$ is continuous, or

(b) if $\left\{x_{n}\right\}$ is a sequence in $X$ such that $x_{n} \rightarrow x, \eta\left(x_{n}, f x_{n}\right) \leq 1$ for all $n$, then $\eta(x, f x) \leq 1$.

If there exists $x_{0} \in X$ such that $\eta\left(x_{0}, f x_{0}\right) \leq 1$, then $f$ has a fixed point.

From Corollary 2.1, we can deduce the following corollary.

Corollary 2.9 Let $(X, d)$ be a complete metric space, and let $f: X \rightarrow X$ be an $\alpha$-admissible mapping. Assume that there exists a function $\beta:[0, \infty) \rightarrow[0,1]$ such that for any bounded sequence $\left\{t_{n}\right\}$ of positive reals, $\beta\left(t_{n}\right) \rightarrow 1$ implies that $t_{n} \rightarrow 0$ and

$$
x, y \in X, \quad \alpha(x, f x) \alpha(y, f y) \geq 1 \quad \Longrightarrow \quad d(f x, f y) \leq \beta(d(x, y)) d(x, y) .
$$

\section{Suppose that either}

(a) $f$ is continuous, or

(b) if $\left\{x_{n}\right\}$ is a sequence in $X$ such that $x_{n} \rightarrow x, \alpha\left(x_{n}, x_{n+1}\right) \geq 1$ for all $n$, then $\alpha(x, f x) \geq 1$.

If there exists $x_{0} \in X$ such that $\alpha\left(x_{0}, f x_{0}\right) \geq 1$, then $f$ has a fixed point.

Also, from the corollary above, we can deduce the following corollaries. 
Corollary 2.10 (Theorem 4 of [9]) Let $(X, d)$ be a complete metric space, and let $f: X \rightarrow X$ be an $\alpha$-admissible mapping. Assume that there exists a function $\beta:[0, \infty) \rightarrow[0,1]$ such that for any bounded sequence $\left\{t_{n}\right\}$ of positive reals, $\beta\left(t_{n}\right) \rightarrow 1$ implies that $t_{n} \rightarrow 0$ and

$$
(d(f x, f y)+\ell)^{\alpha(x, f x) \alpha(y, f y)} \leq \beta(d(x, y)) d(x, y)+\ell
$$

for all $x, y \in X$, where $\ell \geq 1$. Suppose that either

(a) $f$ is continuous, or

(b) if $\left\{x_{n}\right\}$ is a sequence in $X$ such that $x_{n} \rightarrow x, \alpha\left(x_{n}, x_{n+1}\right) \geq 1$ for all $n$, then $\alpha(x, f x) \geq 1$. If there exists $x_{0} \in X$ such that $\alpha\left(x_{0}, f x_{0}\right) \geq 1$, then $f$ has a fixed point.

Corollary 2.11 (Theorem 6 of [9]) Let $(X, d)$ be a complete metric space, and let $f: X \rightarrow X$ be an $\alpha$-admissible mapping. Assume that there exists a function $\beta:[0, \infty) \rightarrow[0,1]$ such that for any bounded sequence $\left\{t_{n}\right\}$ of positive reals, $\beta\left(t_{n}\right) \rightarrow 1$ implies that $t_{n} \rightarrow 0$ and

$$
(\alpha(x, f x) \alpha(y, f y)+1)^{d(f x, f y)} \leq 2^{\beta(d(x, y)) d(x, y)}
$$

for all $x, y \in X$. Suppose that either

(a) $f$ is continuous, or

(b) if $\left\{x_{n}\right\}$ is a sequence in $X$ such that $x_{n} \rightarrow x, \alpha\left(x_{n}, x_{n+1}\right) \geq 1$ for all $n$, then $\alpha(x, f x) \geq 1$. If there exists $x_{0} \in X$ such that $\alpha\left(x_{0}, f x_{0}\right) \geq 1$, then $f$ has a fixed point.

Corollary 2.12 (Theorem 8 of [9]) Let $(X, d)$ be a metric space such that $(X, d)$ is complete, and let $f: X \rightarrow X$ be an $\alpha$-admissible mapping. Assume that there exists a function $\beta$ : $[0, \infty) \rightarrow[0,1]$ such that for any bounded sequence $\left\{t_{n}\right\}$ of positive reals, $\beta\left(t_{n}\right) \rightarrow 1$ implies that $t_{n} \rightarrow 0$ and

$$
\alpha(x, f x) \alpha(y, f y) d(f x, f y) \leq \beta(d(x, y)) d(x, y)
$$

for all $x, y \in X$. Suppose that either

(a) $f$ is continuous, or

(b) if $\left\{x_{n}\right\}$ is a sequence in $X$ such that $x_{n} \rightarrow x, \alpha\left(x_{n}, f x_{n}\right) \geq 1$ for all $n$, then $\alpha(x, f x) \geq 1$.

If there exists $x_{0} \in X$ such that $\alpha\left(x_{0}, f x_{0}\right) \geq 1$, then $f$ has a fixed point.

Example 2.1 Let $X=[0, \infty)$ be endowed with the usual metric $d(x, y)=|x-y|$ for all $x, y \in$ $X$, and let $f: X \rightarrow X$ be defined by

$$
f x= \begin{cases}\frac{1}{4} x & \text { if } x \in[0,1], \\ \ln \left(x^{2}+x+3\right) & \text { if } x \in(1, \infty) .\end{cases}
$$

Define also $\alpha: X \times X \rightarrow[0,+\infty)$ and $\psi:[0, \infty) \rightarrow[0, \infty)$ by

$$
\alpha(x, y)=\left\{\begin{array}{ll}
6 & \text { if } x, y \in[0,1], \\
0 & \text { otherwise }
\end{array} \text { and } \quad \beta(t)=\frac{1}{2} .\right.
$$

We prove that Corollary 2.9 can be applied to $f$, but Corollaries 2.10, 2.11 and 2.12 (Theorem 4, 6 and 8 of [9]) cannot be applied to $f$. 
Clearly, $(X, d)$ is a complete metric space. We show that $f$ is an $\alpha$-admissible mapping. Let $x, y \in X$ with $\alpha(x, y) \geq 1$, then $x, y \in[0,1]$. On the other hand, for all $x \in[0,1]$, we have $f x \leq 1$. It follows that $\alpha(f x, f y) \geq 1$. Hence, the assertion holds. Also, $\alpha(0, f 0) \geq 1$. Now, if $\left\{x_{n}\right\}$ is a sequence in $X$ such that $\alpha\left(x_{n}, x_{n+1}\right) \geq 1$ for all $n \in \mathbb{N} \cup\{0\}$ and $x_{n} \rightarrow x$ as $n \rightarrow+\infty$, then $\left\{x_{n}\right\} \subset[0,1]$, and hence $x \in[0,1]$. This implies that $\alpha\left(x_{n}, x\right) \geq 1$ for all $n \in \mathbb{N}$.

Let $\alpha(x, y) \geq 1$. Then $x, y \in[0,1]$. We get,

$$
d(f x, f y)=|f y-f x|=\left|\frac{1}{4} x-\frac{1}{4} y\right|=\frac{1}{4}|x-y| \leq \frac{1}{2}|x-y|=\beta(d(x, y)) d(x, y) .
$$

That is,

$$
\alpha(x, y) \geq 1 \quad \Longrightarrow \quad d(f x, f y) \leq \beta(d(x, y)) d(x, y)
$$

then the conditions of Corollary 2.1 hold, and $f$ has a fixed point.

Let $x=0, y=1$, and let $\ell=1$, then

$$
(d(f 0, f 1)+1)^{\alpha(0, f 0) \alpha(1, f 1)}=(1 / 4+1)^{36}>1 / 2+1=\beta(d(0,1)) d(0,1)+1 .
$$

That is, Corollary 2.10 (Theorem 4 of [9]) cannot be applied for this example.

Let, $x=0$, and let $y=1$, then

$$
(\alpha(0, f 0) \alpha(1, f 1)+1)^{d(f 0, f 1)}=\sqrt[4]{37}>\sqrt{2}=2^{\beta(d(0,1)) d(0,1)} .
$$

That is, Corollary 2.11 (Theorem 6 of [9]) cannot be applied for this example.

Let, $x=0$, and let $y=1$, then

$$
\alpha(0, f 0) \alpha(1, f 1) d(f 0, f 1)=9>1 / 2=\beta(d(0,1)) d(0,1) .
$$

That is, Corollary 2.12 (Theorem 8 of [9]) cannot be applied for this example.

\section{Modified $\alpha-\psi$-Meir-Keeler contractive mappings}

Recently, Karapinar et al. [11] introduced the notion of a triangular $\alpha$-admissible mapping as follows.

Definition 3.1 [11] Let $f: X \rightarrow X$, and let $\alpha: X \times X \rightarrow(-\infty,+\infty)$. We say that $f$ is a triangular $\alpha$-admissible mapping if

(T1) $\alpha(x, y) \geq 1$ implies that $\alpha(f x, f y) \geq 1, x, y \in X$;

(T2) $\left\{\begin{array}{l}\alpha(x, z) \geq 1, \\ \alpha(z, y) \geq 1\end{array}\right.$ implies that $\alpha(x, y) \geq 1$.

Lemma 3.1 [11] Let $f$ be a triangular $\alpha$-admissible mapping. Assume that there exists $x_{0} \in X$ such that $\alpha\left(x_{0}, f x_{0}\right) \geq 1$. Define sequence $\left\{x_{n}\right\}$ by $x_{n}=f^{n} x_{0}$. Then

$$
\alpha\left(x_{m}, x_{n}\right) \geq 1 \text { for all } m, n \in \mathbb{N} \text { with } m<n .
$$

Denote with $\Psi$ the family of nondecreasing functions $\psi:[0,+\infty) \rightarrow[0,+\infty)$ continuous at $t=0$ such that 
- $\psi(t)=0$ if and only if $t=0$,

- $\psi(t+s) \leq \psi(t)+\psi(s)$.

Definition 3.2 [11] Let $(X, d)$ be a metric space, and let $\psi \in \Psi$. Suppose that $f: X \rightarrow X$ is a triangular $\alpha$-admissible mapping satisfying the following condition:

for each $\varepsilon>0$ there exists $\delta>0$ such that

$$
\varepsilon \leq \psi(d(x, y))<\varepsilon+\delta \quad \text { implies that } \quad \alpha(x, y) \psi(d(f x, f y))<\varepsilon
$$

for all $x, y \in X$. Then $f$ is called an $\alpha$ - $\psi$-Meir-Keeler contractive mapping.

Now, we modify Definition 3.2 as follows.

Definition 3.3 Let $(X, d)$ be a metric space, and let $\psi \in \Psi$. Suppose that $f: X \rightarrow X$ is a triangular $\alpha$-admissible mapping satisfying the following condition:

for each $\varepsilon>0$ there exists $\delta>0$ such that

$$
\varepsilon \leq \psi(d(x, y))<\varepsilon+\delta \quad \text { implies that } \quad \psi(d(f x, f y))<\varepsilon
$$

for all $x, y \in X$ with $\alpha(x, y) \geq 1$. Then $f$ is called a modified $\alpha$ - $\psi$-Meir-Keeler contractive mapping.

Remark 3.1 Let $f$ be a modified $\alpha$ - $\psi$-Meir-Keeler contractive mapping. Then

$$
\psi(d(f x, f y))<\psi(d(x, y))
$$

for all $x, y \in X$ when $x \neq y$ and $\alpha(x, y) \geq 1$. Also, if $x=y$ and $\alpha(x, y) \geq 1$, then $d(f x, f y)=0$, i.e.,

$$
\psi(d(f x, f y)) \leq \psi(d(x, y))
$$

Theorem 3.1 Let $(X, d)$ be a complete metric space. Suppose that $f$ is a continuous modified $\alpha-\psi$-Meir-Keeler contractive mapping, and that there exists $x_{0} \in X$ such that $\alpha\left(x_{0}, f x_{0}\right) \geq 1$, then $f$ has a fixed point.

Proof Let $x_{0} \in X$ and define a sequence $\left\{x_{n}\right\}$ by $x_{n}=f^{n} x_{0}$ for all $n \in \mathbb{N}$. If $x_{n_{0}}=x_{n_{0}+1}$ for some $n_{0} \in \mathbb{N} \cup\{0\}$, then, obviously, $f$ has a fixed point. Hence, we suppose that

$$
x_{n} \neq x_{n+1}
$$

for all $n \in \mathbb{N} \cup\{0\}$. We have $d\left(x_{n}, x_{n+1}\right)>0$ for all $n \in \mathbb{N} \cup\{0\}$. Now, define $s_{n}=\psi\left(d\left(x_{n}, x_{n+1}\right)\right)$. By Remark 3.1, we deduce that for all $n \in \mathbb{N} \cup\{0\} \psi\left(d\left(x_{n+1}, x_{n+2}\right)\right)=\psi\left(d\left(f x_{n}, f x_{n+1}\right)\right)<$ $\psi\left(d\left(x_{n}, x_{n+1}\right)\right)$. By applying Lemma 3.1 for

$$
\alpha\left(x_{m}, x_{n}\right) \geq 1 \quad \text { for all } m, n \in \mathbb{N} \text { with } m<n,
$$


we have

$$
\psi\left(d\left(x_{n+1}, x_{n+2}\right)\right)<\psi\left(d\left(x_{n}, x_{n+1}\right)\right) .
$$

Hence, the sequence $\left\{s_{n}\right\}$ is decreasing in $\mathbb{R}_{+}$, and so, it is convergent to $s \in \mathbb{R}_{+}$. We will show that $s=0$. Suppose, to the contrary, that $s>0$. Note that

$$
0<s<\psi\left(d\left(x_{n}, x_{n+1}\right)\right) \quad \text { for all } n \in \mathbb{N} \cup\{0\} \text {. }
$$

Let $\varepsilon=s>0$. Then by hypothesis, there exists a $\delta(\varepsilon)>0$ such that (3.2) holds. On the other hand, by the definition of $\varepsilon$, there exists $n_{0} \in \mathbb{N}$ such that

$$
\varepsilon<s_{n_{0}}=\psi\left(d\left(x_{n_{0}}, x_{n_{0}+1}\right)\right)<\varepsilon+\delta .
$$

Now by (3.2), we have

$$
s_{n_{0}+1}=\psi\left(d\left(x_{n_{0}+1}, x_{n_{0}+2}\right)\right) \leq \psi\left(d\left(f x_{n_{0}}, f x_{n_{0}+1}\right)\right)<\varepsilon=s,
$$

which is a contradiction. Hence $s=0$, that is, $\lim _{n \rightarrow+\infty} s_{n}=0$. Now, by the continuity of $\psi$ at $t=0$, we have $\lim _{n \rightarrow+\infty} d\left(x_{n}, x_{n+1}\right)=0$. For given $\varepsilon>0$, by the hypothesis, there exists a $\delta=\delta(\varepsilon)>0$ such that (3.2) holds. Without loss of generality, we assume that $\delta<\varepsilon$. Since $s=0$, then there exists $N \in \mathbb{N}$ such that

$$
s_{n-1}=\psi\left(d\left(x_{n-1}, x_{n}\right)\right)<\delta \quad \text { for all } n \geq N .
$$

We will prove that for any fixed $k \geq N_{0}$,

$$
\psi\left(d\left(x_{k}, x_{k+l}\right)\right) \leq \varepsilon \quad \text { for all } l \in \mathbb{N},
$$

holds. Note that (3.6) holds for $l=1$ by (3.5). Suppose that condition (3.2) is satisfied for some $m \in \mathbb{N}$. For $l=m+1$, by (3.5), we get

$$
\begin{aligned}
\psi\left(d\left(x_{k-1}, x_{k+m}\right)\right) & \leq \psi\left(d\left(x_{k-1}, x_{k}\right)+d\left(x_{k}, x_{k+m}\right)\right) \\
& \leq \psi\left(d\left(x_{k-1}, x_{k}\right)\right)+\psi\left(d\left(x_{k}, x_{k+m}\right)\right) \\
& <\varepsilon+\delta .
\end{aligned}
$$

If $\psi\left(d\left(x_{k-1}, x_{k+m}\right)\right) \geq \varepsilon$, then by (3.2), we get

$$
\psi\left(d\left(x_{k}, x_{k+m+1}\right)\right)=\psi\left(d\left(f x_{k-1}, f x_{k+m}\right)\right)<\varepsilon,
$$

and hence (3.6) holds.

If $\psi\left(d\left(x_{k-1}, x_{k+m}\right)\right)<\varepsilon$, by Remark 3.1, we get

$$
\psi\left(d\left(x_{k}, x_{k+m+1}\right)\right) \leq \psi\left(d\left(x_{k-1}, x_{k+m}\right)\right)<\varepsilon .
$$


Consequently, (3.6) holds for $l=m+1$. Hence, $\psi\left(d\left(x_{k}, x_{k+l}\right)\right) \leq \varepsilon$ for all $k \geq N_{0}$ and $l \geq 1$, which means

$$
d\left(x_{n}, x_{m}\right)<\varepsilon \quad \text { for all } m \geq n \geq N_{0} .
$$

Hence $\left\{x_{n}\right\}$ is a Cauchy sequence. Since $(X, d)$ is complete, there exists $z \in X$ such that $x_{n} \rightarrow z$ as $n \rightarrow \infty$. Now, since $f$ is continuous, then

$$
f z=f\left(\lim _{n \rightarrow \infty} x_{n}\right)=\lim _{n \rightarrow \infty} x_{n+1}=z
$$

that is, $f$ has a fixed point.

Corollary 3.1 (Theorem 10 of [11]) Let $(X, d)$ be a complete metric space. Suppose that $f$ is a continuous $\alpha-\psi$-Meir-Keeler contractive mapping, and that there exists $x_{0} \in X$ such that $\alpha\left(x_{0}, f x_{0}\right) \geq 1$, then $f$ has a fixed point.

Proof Let $\varepsilon \leq \psi(d(x, y))<\varepsilon+\delta$, where $\alpha(x, y) \geq 1$. Then by $\varepsilon \leq \psi(d(x, y))<\varepsilon+\delta$ and Definition 3.2, we deduce that $\alpha(x, y) \psi(d(f x, f y))<\varepsilon$. On the other hand, since $\alpha(x, y) \geq 1$, then we have

$$
\psi(d(f x, f y)) \leq \alpha(x, y) \psi(d(f x, f y))<\varepsilon
$$

That is, conditions of Theorem 3.1 hold, and $f$ has a fixed point.

Theorem 3.2 Let $(X, d)$ be a complete metric space, and let $f$ be a modified $\alpha-\psi$-MeirKeeler contractive mapping. If the following conditions hold:

(i) there exists $x_{0} \in X$ such that $\alpha\left(x_{0}, f x_{0}\right) \geq 1$,

(ii) if $\left\{x_{n}\right\}$ is a sequence in $X$ such that $\alpha\left(x_{n}, x_{n+1}\right) \geq 1$ for all $n$, and $x_{n} \rightarrow x$ as $n \rightarrow+\infty$, then $\alpha\left(x_{n}, x\right) \geq 1$ for all $n$.

Then $f$ has a fixed point.

Proof Following the proof of Theorem 3.1, we say that $\alpha\left(x_{n}, x_{n+1}\right) \geq 1$ for all $n \in \mathbb{N} \cup\{0\}$, and that there exist $z \in X$ such that $x_{n} \rightarrow z$ as $n \rightarrow+\infty$. Hence, from (ii) $\alpha\left(x_{n}, z\right) \geq 1$. By Remark 3.1, we have

$$
\begin{aligned}
\psi(d(f z, z)) & \leq \psi\left(d\left(f z, f x_{n}\right)+d\left(f x_{n}, z\right)\right) \leq \psi\left(d\left(f z, f x_{n}\right)\right)+\psi\left(d\left(f x_{n}, z\right)\right) \\
& \leq \psi\left(d\left(z, x_{n}\right)\right)+\psi\left(d\left(x_{n+1}, z\right)\right) .
\end{aligned}
$$

By taking limit as $n \rightarrow+\infty$, in the inequality above, we get $\psi(d(f z, z)) \leq 0$, that is, $d(f z, z)=0$. Hence $f z=z$.

Corollary 3.2 (Theorem 11 of [11]) Let $(X, d)$ be a complete metric space, and let $f$ be a $\alpha-\psi$-Meir-Keeler contractive mapping. If the following conditions hold:

(i) there exists $x_{0} \in X$ such that $\alpha\left(x_{0}, f x_{0}\right) \geq 1$,

(ii) if $\left\{x_{n}\right\}$ is a sequence in $X$ such that $\alpha\left(x_{n}, x_{n+1}\right) \geq 1$ for all $n$, and $x_{n} \rightarrow x$ as $n \rightarrow+\infty$, then $\alpha\left(x_{n}, x\right) \geq 1$ for all $n$.

Then $f$ has a fixed point. 
Example 3.1 Let $X=[0, \infty)$, and let $d(x, y)=|x-y|$ be a metric on $X$. Define $f: X \rightarrow X$ by

$$
f x=\left\{\begin{array}{ll}
\frac{x}{5} & \text { if } x \in[0,1], \\
x^{x^{2}+1} & x \in(1, \infty),
\end{array} \text { and } \quad \alpha(x, y)= \begin{cases}10 & \text { if } x, y \in[0,1] \\
-2 & \text { otherwise }\end{cases}\right.
$$

and $\psi(t)=\frac{1}{4} t$. Clearly, $(X, d)$ is a complete metric space. We show that $f$ is a triangular $\alpha$-admissible mapping. Let $x, y \in X$, if $\alpha(x, y) \geq 1$, then $x, y \in[0,1]$. On the other hand, for all $x, y \in[0,1]$, we have $f x \leq 1$ and $f y \leq 1$. It follows that $\alpha(f x, f y) \geq 1$. Also, if $\alpha(x, z) \geq 1$ and $\alpha(z, y) \geq 1$, then $x, y, z \in[0,1]$, and hence, $\alpha(x, y) \geq 1$. Thus the assertion holds by the same arguments. Notice that $\alpha(0, f 0) \geq 1$.

Now, if $\left\{x_{n}\right\}$ is a sequence in $X$ such that $\alpha\left(x_{n}, x_{n+1}\right) \geq 1$ for all $n \in \mathbb{N} \cup\{0\}$, and $x_{n} \rightarrow x$ as $n \rightarrow+\infty$, then $\left\{x_{n}\right\} \subset[0,1]$, and hence $x \in[0,1]$. This implies that $\alpha\left(x_{n}, x\right) \geq 1$ for all $n \in \mathbb{N} \cup\{0\}$. Let $\alpha(x, y) \geq 1$, then $x, y \in[0,1]$. Without loss of generality, take $x \leq y$. Then

$$
\begin{aligned}
& \psi(d(f x, f y))=\frac{y}{20}-\frac{x}{20}, \\
& \psi(d(x, y))=\frac{y}{4}-\frac{x}{4} .
\end{aligned}
$$

Clearly, by taking $\delta=4 \varepsilon$, the condition (3.2) holds. Hence, conditions of Theorem 3.2 hold, and $f$ has a fixed point. But if $x, y \in[0,1]$ and

$$
\varepsilon \leq d(x, y)<\varepsilon+\delta
$$

where $\varepsilon>0$ and $\delta>0$. Then

$$
\alpha(x, y) d(f x, f y)=2|x-y|=2 d(x, y) \geq 2 \varepsilon .
$$

That is, Corollary 3.2 (Theorem 11 of [11]) cannot be applied for this example.

Denote with $\Psi_{\mathrm{st}}$ the family of strictly nondecreasing functions $\psi_{\mathrm{st}}:[0,+\infty) \rightarrow[0,+\infty)$ continuous at $t=0$ such that

- $\psi_{\mathrm{st}}(t)=0$ if and only if $t=0$,

- $\psi_{\mathrm{st}}(t+s) \leq \psi_{\mathrm{st}}(t)+\psi_{\mathrm{st}}(s)$.

Definition 3.4 [11] Let $(X, d)$ be a metric space, and let $\psi_{\text {st }} \in \Psi_{\text {st }}$. Suppose that $f: X \rightarrow X$ is a triangular $\alpha$-admissible mapping satisfying the following condition:

for each $\varepsilon>0$, there exists $\delta>0$ such that

$$
\varepsilon \leq \psi_{\text {st }}(M(x, y))<\varepsilon+\delta \quad \text { implies that } \quad \alpha(x, y) \psi_{\text {st }}(d(f x, f y))<\varepsilon
$$

for all $x, y \in X$, where

$$
M(x, y)=\max \left\{d(x, y), d(f x, x), d(f y, y), \frac{1}{2}[d(f x, y)+d(x, f y)]\right\} .
$$

Then $f$ is called a generalized $\alpha-\psi_{\mathrm{st}}$-Meir-Keeler contractive mapping. 
Definition 3.5 Let $(X, d)$ be a metric space, and let $\psi_{\text {st }} \in \Psi_{\text {st }}$. Suppose that $f: X \rightarrow X$ is a triangular $\alpha$-admissible mapping satisfying the following condition:

for each $\varepsilon>0$ there exists $\delta>0$ such that

$$
\varepsilon \leq \psi_{\mathrm{st}}(M(x, y))<\varepsilon+\delta \quad \text { implies that } \quad \psi_{\mathrm{st}}(d(f x, f y))<\varepsilon
$$

for all $x, y \in X$, where $\alpha(x, y) \geq 1$ and

$$
M(x, y)=\max \left\{d(x, y), d(f x, x), d(f y, y), \frac{1}{2}[d(f x, y)+d(x, f y)]\right\} .
$$

Then $f$ is called a modified generalized $\alpha-\psi_{\text {st }}$-Meir-Keeler contractive mapping.

Remark 3.2 Let $f$ be a modified generalized $\alpha-\psi_{\mathrm{st}}$-Meir-Keeler contractive mapping. Then

$$
\psi_{\text {st }}(d(f x, f y))<\psi_{\text {st }}(M(x, y))
$$

for all $x, y \in X$, where $\alpha(x, y) \geq 1$ when $M(x, y)>0$. Also, if $M(x, y)=0$ and $\alpha(x, y) \geq 1$, then $x=y$, which implies that $\psi(d(f x, f y))=0$, i.e.,

$$
\psi_{\mathrm{st}}(d(f x, f y)) \leq \psi_{\mathrm{st}}(M(x, y)) .
$$

Proposition 3.1 Let $(X, d)$ be a metric space, and let $f: X \rightarrow X$ be a modified generalized $\alpha-\psi_{\mathrm{st}}-$ Meir-Keeler contractive mapping. If there exists $x_{0} \in X$ such that $\alpha\left(x_{0}, f x_{0}\right) \geq 1$, then $\lim _{n \rightarrow \infty} d\left(f^{n+1} x_{0}, f^{n} x_{0}\right)=0$.

Proof Define a sequence $\left\{x_{n}\right\}$ by $x_{n}=f^{n} x_{0}$ for all $n \in \mathbb{N}$. If $x_{n_{0}}=x_{n_{0}+1}$ for some $n_{0} \in \mathbb{N} \cup\{0\}$, then, obviously, the conclusion holds. Hence, we suppose that

$$
x_{n} \neq x_{n+1}
$$

for all $n \in \mathbb{N} \cup\{0\}$. Then we have $M\left(x_{n+1}, x_{n}\right)>0$ for every $n \geq 0$. Then by Lemma 3.1 and Remark 3.2, we have

$$
\begin{aligned}
\psi_{\mathrm{st}}\left(d\left(x_{n+1}, x_{n+2}\right)\right)= & \psi_{\mathrm{st}}\left(d\left(f x_{n}, f x_{n+1}\right)\right)<\psi_{\mathrm{st}}\left(M\left(x_{n}, x_{n+1}\right)\right) \\
= & \psi_{\mathrm{st}}\left(\operatorname { m a x } \left\{d\left(x_{n}, x_{n+1}\right), d\left(f x_{n}, x_{n}\right), d\left(f x_{n+1}, x_{n+1}\right),\right.\right. \\
& \left.\left.\frac{1}{2}\left[d\left(f x_{n}, x_{n+1}\right)+d\left(x_{n}, f x_{n+1}\right)\right]\right\}\right) \\
\leq & \psi_{\mathrm{st}}\left(\max \left\{d\left(x_{n}, x_{n+1}\right), d\left(x_{n+1}, x_{n+2}\right)\right\}\right) .
\end{aligned}
$$

Now, since $\psi_{\text {st }}$ is strictly nondecreasing, then we get

$$
d\left(x_{n+2}, x_{n+1}\right)<\max \left\{d\left(x_{n+1}, x_{n}\right), d\left(x_{n+2}, x_{n+1}\right)\right\} .
$$


Hence the case, where

$$
\max \left\{d\left(x_{n+1}, x_{n}\right), d\left(x_{n+2}, x_{n+1}\right)\right\}=d\left(x_{n+2}, x_{n+1}\right),
$$

is not possible. Therefore, we deduce that

$$
d\left(x_{n+2}, x_{n+1}\right)<d\left(x_{n+1}, x_{n}\right)
$$

for all $n$. That is, $\left\{d\left(x_{n+1}, x_{n}\right)\right\}_{n=0}^{\infty}$ is a decreasing sequence in $\mathbb{R}_{+}$, and it converges to $\varepsilon \in \mathbb{R}_{+}$, that is,

$$
\lim _{n \rightarrow \infty} \psi_{\text {st }}\left(d\left(x_{n+1}, x_{n}\right)\right)=\lim _{n \rightarrow \infty} \psi_{\text {st }}\left(M\left(x_{n+1}, x_{n}\right)\right)=\psi_{\text {st }}(\varepsilon) .
$$

Notice that $\varepsilon=\inf \left\{d\left(x_{n}, x_{n+1}\right): n \in \mathbb{N}\right\}$. Let us prove that $\varepsilon=0$. Suppose, to the contrary, that $\varepsilon>0$. Then $\psi(\varepsilon)>0$. Considering (3.13) together with the assumption that $f$ is a generalized $\alpha-\psi_{\mathrm{st}}$-Meir-Keeler contractive mapping, for $\psi_{\mathrm{st}}(\varepsilon)$, there exists $\delta>0$ and a natural number $m$ such that

$$
\psi_{\mathrm{st}}(\varepsilon) \leq \psi_{\mathrm{st}}\left(M\left(x_{m}, x_{m+1}\right)\right)<\psi_{\mathrm{st}}(\varepsilon)+\delta
$$

implies that

$$
\psi_{\mathrm{st}}\left(d\left(x_{m+1}, x_{m+2}\right)\right)=\psi_{\mathrm{st}}\left(d\left(f x_{m}, f x_{m+1}\right)\right)<\psi_{\mathrm{st}}(\varepsilon) .
$$

Now, since $\psi_{\text {st }}$ is strictly nondecreasing, then we get

$$
d\left(x_{m+2}, x_{m+1}\right)<\varepsilon,
$$

which is a contradiction, since $\varepsilon=\inf \left\{d\left(x_{n}, x_{n+1}\right): n \in \mathbb{N}\right\}$. Then $\varepsilon=0$, and so,

$$
\lim _{n \rightarrow \infty} d\left(x_{n+1}, x_{n}\right)=0
$$

Theorem 3.3 Let $(X, d)$ be a complete metric space, and let $f: X \rightarrow X$ be an orbitally continuous modified generalized $\alpha-\psi_{\text {st }}-$ Meir-Keeler contractive mapping. If there exist $x_{0} \in$ $X$ such that $\alpha\left(x_{0}, f x_{0}\right) \geq 1$, then $f$ has a fixed point.

Proof Define $x_{n+1}=f^{n+1} x_{0}$ for all $n \geq 0$. We want to prove that $\lim _{m, n \rightarrow \infty} d\left(x_{n}, x_{m}\right)=0$. If this is not so, then there exist $\varepsilon>0$ and a subsequence $\left\{x_{n(i)}\right\}$ of $\left\{x_{n}\right\}$ such that

$$
d\left(x_{n(i)}, x_{n(i+1)}\right)>2 \varepsilon .
$$

For this $\varepsilon>0$, there exists $\delta>0$ such that $\varepsilon \leq \psi_{\text {st }}(M(x, y))<\varepsilon+\delta$ implies that $\alpha(x, y) \psi_{\mathrm{st}}(d(f x, f y))<\varepsilon$. Put $r=\min \{\varepsilon, \delta\}$ and $s_{n}=d\left(x_{n}, x_{n+1}\right)$ for all $n \geq 1$. From Proposition 3.1, there exists $n_{0}$ such that

$$
s_{n}=d\left(x_{n}, x_{n+1}\right)<\frac{r}{4}
$$


for all $n \geq n_{0}$. Let $n(i)>n_{0}$. We get $n(i) \leq n(i+1)-1$. If $d\left(x_{n(i)}, x_{n(i+1)-1}\right) \leq \varepsilon+\frac{r}{2}$, then

$$
\begin{aligned}
d\left(x_{n(i)}, x_{n(i+1)}\right) & \leq d\left(x_{n(i)}, x_{n(i+1)-1}\right)+d\left(x_{n(i+1)-1}, x_{n(i+1)}\right) \\
& \leq d\left(x_{n(i)}, x_{n(i+1)-1}\right)+d\left(x_{n(i+1)-1}, x_{n(i+1)}\right) \\
& <\varepsilon+\frac{r}{2}+s_{n(i+1)-1}<\varepsilon+\frac{3 r}{4}<2 \varepsilon,
\end{aligned}
$$

which contradicts the assumption (3.14). Therefore, there are values of $k$ such that $n(i) \leq$ $k \leq n(i+1)$ and $d\left(x_{n(i)}, x_{k}\right)>\varepsilon+\frac{r}{2}$. Now if $d\left(x_{n(i)}, x_{n(i)+1}\right) \geq \varepsilon+\frac{r}{2}$, then

$$
s_{n(i)}=d\left(x_{n(i)}, x_{n(i)+1}\right) \geq \varepsilon+\frac{r}{2}>r+\frac{r}{2}>\frac{r}{4},
$$

which is a contradiction to (3.15). Hence, there are values of $k$ with $n(i) \leq k \leq n(i+1)$ such that $d\left(x_{n(i)}, x_{k}\right)<\varepsilon+\frac{r}{2}$. Choose the smallest integer $k$ with $k \geq n(i)$ such that $d\left(x_{n(i)}, x_{k}\right) \geq$ $\varepsilon+\frac{r}{2}$. Thus, $d\left(x_{n(i)}, x_{k-1}\right)<\varepsilon+\frac{r}{2}$, and so,

$$
\begin{aligned}
d\left(x_{n(i)}, x_{k}\right) & \leq d\left(x_{n(i)}, x_{k-1}\right)+d\left(x_{k-1}, x_{k}\right) \\
& \leq d\left(x_{n(i)}, x_{k-1}\right)+d\left(x_{k-1}, x_{k}\right)<\varepsilon+\frac{r}{2}+\frac{r}{4}=\varepsilon+\frac{3 r}{4} .
\end{aligned}
$$

Now, we can choose a natural number $k$ satisfying $n(i) \leq k \leq n(i+1)$ such that

$$
\varepsilon+\frac{r}{2} \leq d\left(x_{n(i)}, x_{k}\right)<\varepsilon+\frac{3 r}{4}
$$

Therefore, we obtain

$$
\begin{aligned}
& d\left(x_{n(i)}, x_{k}\right)<\varepsilon+\frac{3 r}{4}<\varepsilon+r \\
& d\left(x_{n(i)}, x_{n(i)+1}\right)=d_{n(i)}<\frac{r}{4}<\varepsilon+r,
\end{aligned}
$$

and

$$
d\left(x_{k}, x_{k+1}\right)=d_{k}<\frac{r}{4}<\varepsilon+r .
$$

Thus, we have

$$
\begin{aligned}
\frac{1}{2}\left[d\left(x_{n(i)}, x_{k+1}\right)+d\left(x_{n(i)+1}, x_{k}\right)\right] \leq & \frac{1}{2}\left[d\left(x_{n(i)}, x_{k}\right)+d\left(x_{k}, x_{k+1}\right)\right. \\
& \left.+d\left(x_{n(i)+1}, x_{n(i)}\right)+d\left(x_{n(i)}, x_{k}\right)\right] \\
\leq & \frac{1}{2}\left[d\left(x_{n(i)}, x_{k}\right)+d\left(x_{k}, x_{k+1}\right)\right. \\
& \left.+d\left(x_{n(i)+1}, x_{n(i)}\right)+d\left(x_{n(i)}, x_{k}\right)\right] \\
= & d\left(x_{n(i)}, x_{k}\right)+\frac{1}{2}\left[s_{k}+s_{n(i)}\right] \\
< & \varepsilon+\frac{3 r}{4}+\frac{1}{2}\left[\frac{r}{4}+\frac{r}{4}\right]=\varepsilon+r .
\end{aligned}
$$


Now, inequalities (3.17)-(3.20) imply that $M\left(x_{n(i)}, x_{k}\right)<\varepsilon+r \leq \varepsilon+\delta$, and so, $\psi_{\mathrm{st}}\left(M\left(x_{n(i)}\right.\right.$, $\left.\left.x_{k}\right)\right)<\psi_{\text {st }}(\varepsilon+\delta) \leq \psi_{\text {st }}(\varepsilon)+\psi_{\text {st }}(\delta)$; the fact that $f$ is a modified generalized $\alpha-\psi_{\text {st }}-$ MeirKeeler contractive mapping yields that

$$
\psi_{\mathrm{st}}\left(d\left(x_{n(i)+1}, x_{k+1}\right)\right)<\psi_{\mathrm{st}}(\varepsilon)
$$

Then $d\left(x_{n(i)+1}, x_{k+1}\right)<\varepsilon$. We deduce

$$
\begin{aligned}
d\left(f^{n(i)} x_{0}, f^{k} x_{0}\right) \leq & d\left(f^{n(i)} x_{0}, f^{n(i)+1} x_{0}\right)+d\left(f^{n(i)+1} x_{0}, f^{k} x_{0}\right) \\
\leq & d\left(f^{n(i)} x_{0}, f^{n(i)+1} x_{0}\right)+d\left(f^{n(i)+1} x_{0}, f^{k} x_{0}\right) \\
\leq & d\left(f^{n(i)} x_{0}, f^{n(i)+1} x_{0}\right)+d\left(f^{n(i)+1} x_{0}, f^{k+1} x_{0}\right) \\
& +d\left(f^{k+1} x_{0}, f^{k} x_{0}\right) .
\end{aligned}
$$

From (3.16), (3.18) and (3.19), we obtain

$$
\begin{aligned}
d\left(x_{n(i)+1}, x_{k+1}\right) & \geq d\left(x_{n(i)}, x_{k}\right)-d\left(x_{n(i)}, x_{n(i)+1}\right)-d\left(x_{k}, x_{k+1}\right) \\
& >\varepsilon+\frac{r}{2}-\frac{r}{4}-\frac{r}{4}=\varepsilon,
\end{aligned}
$$

which is a contradiction. We obtained that $\lim _{m, n \rightarrow \infty} d\left(x_{n}, x_{m}\right)=0$, and so, $\left\{x_{n}=f^{n} x_{0}\right\}$ is a Cauchy sequence. Since $X$ is complete, then there exists $z \in X$ such that $f^{n} x_{0} \rightarrow z$ as $n \rightarrow \infty$. As $f$ is orbitally continuous, so $z=f z$.

Corollary 3.3 (Theorem 17 of [11]) Let $(X, d)$ be a complete metric space, and let $f: X \rightarrow$ $X$ be an orbitally continuous generalized $\alpha-\psi_{\mathrm{st}}$-Meir-Keeler contractive mapping. If there exist $x_{0} \in X$ such that $\alpha\left(x_{0}, f x_{0}\right) \geq 1$, then $f$ has a fixed point.

Example 3.2 Let $X=[0, \infty)$, and let $d(x, y)=|x-y|$ be a metric on $X$. Define $f: X \rightarrow X$ by

$$
f x= \begin{cases}\frac{x}{7} & \text { if } x \in[0,1], \\ \frac{x}{\sqrt[3]{x}+6} & x \in(1, \infty)\end{cases}
$$

and $\psi_{\mathrm{st}}(t)=\frac{1}{2} t$,

$$
\alpha(x, y)= \begin{cases}28 & \text { if } x, y \in[0,1] \\ -8 & \text { otherwise }\end{cases}
$$

Clearly, $f$ is a triangular $\alpha$-admissible mapping, and it is orbitally continuous. Let $\alpha(x, y) \geq 1$, then $x, y \in[0,1]$. Without loss of generality, take $x \leq y$. Then

$$
\begin{aligned}
\psi_{\text {st }}(d(f x, f y)) & =\frac{y}{14}-\frac{x}{14}, \\
\psi_{\text {st }}(M(x, y)) & =\psi_{\text {st }}\left(\max \left\{y-x, \frac{6}{7} y, x-\frac{y}{7}, y-\frac{x}{7}\right\}\right) \\
& =\max \left\{\frac{y}{2}-\frac{x}{2}, \frac{6}{14} y, \frac{x}{2}-\frac{y}{14}, \frac{y}{2}-\frac{x}{14}\right\} .
\end{aligned}
$$


Clearly, by taking $\delta=6 \varepsilon$, the condition (3.10) holds. Hence, all conditions of Theorem 3.3 are satisfied, and $f$ has a fixed point. But if $x=0$ and $y=1$

$$
\varepsilon \leq M(0,1)<\delta+\varepsilon
$$

for $\delta>0$ and $\varepsilon>0$, then

$$
\varepsilon \leq 1<\delta+\varepsilon
$$

and so,

$$
\alpha(0,1) \psi_{\text {st }}(d(f 0, f 1))=2 \geq 1 \geq \varepsilon .
$$

That is, Corollary 3.3 (Theorem 17 of [11]) cannot be applied for this example.

\section{Modified $\alpha-\eta$-contractive multifunction}

Recently, Asl et al. [12] introduced the following notion.

Definition 4.1 Let $T: X \rightarrow 2^{X}$, and let $\alpha: X \times X \rightarrow \mathbb{R}_{+}$. We say that $T$ is an $\alpha_{*}$-admissible mapping if

$$
\alpha(x, y) \geq 1 \quad \text { implies that } \quad \alpha_{*}(T x, T y) \geq 1, \quad x, y \in X,
$$

where

$$
\alpha_{*}(A, B)=\inf _{x \in A, y \in B} \alpha(x, y)
$$

We generalize this concept as follows.

Definition 4.2 Let $T: X \rightarrow 2^{X}$ be a multifunction, and let $\alpha, \eta: X \times X \rightarrow \mathbb{R}_{+}$be two functions, where $\eta$ is bounded. We say that $T$ is an $\alpha_{*}$-admissible mapping with respect to $\eta$ if

$$
\alpha(x, y) \geq \eta(x, y) \quad \text { implies that } \quad \alpha_{*}(T x, T y) \geq \eta_{*}(T x, T y), \quad x, y \in X,
$$

where

$$
\alpha_{*}(A, B)=\inf _{x \in A, y \in B} \alpha(x, y) \quad \text { and } \quad \eta_{*}(A, B)=\sup _{x \in A, y \in B} \eta(x, y) .
$$

If we take $\eta(x, y)=1$ for all $x, y \in X$, then this definition reduces to Definition 4.1. In case $\alpha(x, y)=1$ for all $x, y \in X$, then $T$ is called an $\eta_{*}$-subadmissible mapping.

Notice that $\Psi$ is the family of nondecreasing functions $\psi:[0,+\infty) \rightarrow[0,+\infty)$ such that $\sum_{n=1}^{\infty} \psi^{n}(t)<+\infty$ for all $t>0$, where $\psi^{n}$ is the $n$th iterate of $\psi$.

As an application of our new concept, we develop now a fixed point result for a multifunction, which generalizes Theorem 1.1. 
Theorem 4.1 Let $(X, d)$ be a complete metric space, and let $T: X \rightarrow 2^{X}$ be an $\alpha_{*}$ admissible, with respect to $\eta$, and closed-valued multifunction on $X$. Assume that for $\psi \in \Psi$

$$
x, y \in X, \quad \alpha_{*}(T x, T y) \geq \eta_{*}(T x, T y) \quad \Longrightarrow \quad H(T x, T y) \leq \psi(d(x, y)) .
$$

Also, suppose that the following assertions hold:

(i) there exist $x_{0} \in X$ and $x_{1} \in T x_{0}$ such that $\alpha\left(x_{0}, x_{1}\right) \geq \eta\left(x_{0}, x_{1}\right)$;

(ii) for a sequence $\left\{x_{n}\right\} \subset X$ converging to $x \in X$ and $\alpha\left(x_{n}, x_{n+1}\right) \geq \eta\left(x_{n}, x_{n+1}\right)$ for all $n \in \mathbb{N}$, we have $\alpha\left(x_{n}, x\right) \geq \eta\left(x_{n}, x\right)$ for all $n \in \mathbb{N}$.

Then $T$ has a fixed point.

Proof Let $x_{1} \in T x_{0}$ be such that $\alpha\left(x_{0}, x_{1}\right) \geq \eta\left(x_{0}, x_{1}\right)$. Since $T$ is an $\alpha_{*}$-admissible mapping, then $\alpha_{*}\left(T x_{0}, T x_{1}\right) \geq \eta_{*}\left(T x_{0}, T x_{1}\right)$. Therefore, from (4.1), we have

$$
H\left(T x_{0}, T x_{1}\right) \leq \psi\left(d\left(x_{0}, x_{1}\right)\right)
$$

If $x_{0}=x_{1}$, then $x_{0}$ is a fixed point of $T$. Hence, we assume that $x_{0} \neq x_{1}$. Also, if $x_{1} \in T x_{1}$, then $x_{1}$ is a fixed point of $T$. Assume that $x_{1} \notin T x_{1}$ and $q>1$. Then we have

$$
0<d\left(x_{1}, T x_{1}\right) \leq H\left(T x_{0}, T x_{1}\right)<q H\left(T x_{0}, T x_{1}\right),
$$

and so, by (4.2), we get

$$
0<d\left(x_{1}, T x_{1}\right)<q H\left(T x_{0}, T x_{1}\right) \leq q \psi\left(d\left(x_{0}, x_{1}\right)\right) .
$$

This implies that there exists $x_{2} \in T x_{1}$ such that

$$
0<d\left(x_{1}, x_{2}\right)<q H\left(T x_{0}, T x_{1}\right) \leq q \psi\left(d\left(x_{0}, x_{1}\right)\right) .
$$

Note that $x_{1} \neq x_{2}$ (since $\left.x_{1} \notin T x_{1}\right)$. Also, since $\alpha_{*}\left(T x_{0}, T x_{1}\right) \geq \eta_{*}\left(T x_{0}, T x_{1}\right), x_{1} \in T x_{0}$ and $x_{2} \in T x_{1}$, then $\alpha\left(x_{1}, x_{2}\right) \geq \eta\left(x_{1}, x_{2}\right)$. So $\alpha_{*}\left(T x_{1}, T x_{2}\right) \geq \eta_{*}\left(T x_{1}, T x_{2}\right)$. Therefore, from (4.1), we have

$$
H\left(T x_{1}, T x_{2}\right) \leq \psi\left(d\left(x_{1}, x_{2}\right)\right)
$$

Put $t_{0}=d\left(x_{0}, x_{1}\right)$. Then from (4.3), we have $d\left(x_{1}, x_{2}\right)<q \psi\left(t_{0}\right)$, where $t_{0}>0$. Now, since $\psi$ is strictly increasing, then $\psi\left(d\left(x_{1}, x_{2}\right)\right)<\psi\left(q \psi\left(t_{0}\right)\right)$. Put

$$
q_{1}=\frac{\psi\left(q \psi\left(t_{0}\right)\right)}{\psi\left(d\left(x_{1}, x_{2}\right)\right)}
$$

and so $q_{1}>1$. If $x_{2} \in T x_{2}$, then $x_{2}$ is a fixed point of $T$. Hence, we suppose that $x_{2} \notin T x_{2}$. Then

$$
0<d\left(x_{2}, T x_{2}\right) \leq H\left(T x_{1}, T x_{2}\right)<q_{1} H\left(T x_{1}, T x_{2}\right) .
$$


So there exists $x_{3} \in T x_{2}$ such that

$$
0<d\left(x_{2}, x_{3}\right)<q_{1} H\left(T x_{1}, T x_{2}\right)
$$

and then from (4.4), we get

$$
0<d\left(x_{2}, x_{3}\right)<q_{1} H\left(T x_{1}, T x_{2}\right) \leq q_{1} \psi\left(d\left(x_{1}, x_{2}\right)\right)=\psi\left(q \psi\left(t_{0}\right)\right) .
$$

Again, since $\psi$ is strictly increasing, then $\psi\left(d\left(x_{2}, x_{3}\right)\right)<\psi\left(\psi\left(q \psi\left(t_{0}\right)\right)\right)$. Put

$$
q_{2}=\frac{\psi\left(\psi\left(q \psi\left(t_{0}\right)\right)\right)}{\psi\left(d\left(x_{2}, x_{3}\right)\right)}
$$

So, $q_{2}>1$. If $x_{3} \in T x_{3}$, then $x_{3}$ is a fixed point of $T$. Hence, we assume that $x_{3} \notin T x_{3}$. Then

$$
0<d\left(x_{3}, T x_{3}\right) \leq H\left(T x_{2}, T x_{3}\right)<q_{2} H\left(T x_{2}, T x_{3}\right),
$$

and so, there exists $x_{4} \in T x_{3}$ such that

$$
0<d\left(x_{3}, x_{4}\right) \leq H\left(T x_{2}, T x_{3}\right)<q_{2} H\left(T x_{2}, T x_{3}\right) .
$$

Clearly, $x_{2} \neq x_{3}$. Also again, since $\alpha_{*}\left(T x_{1}, T x_{2}\right) \geq \eta_{*}\left(T x_{1}, T x_{2}\right), x_{2} \in T x_{1}$ and $x_{3} \in T x_{2}$, then $\alpha\left(x_{2}, x_{3}\right) \geq \eta\left(x_{2}, x_{3}\right)$, and so, $\alpha_{*}\left(T x_{2}, T x_{3}\right) \geq \eta_{*}\left(T x_{2}, T x_{3}\right)$. Then from (4.1), we have

$$
H\left(T x_{2}, T x_{3}\right) \leq \psi\left(d\left(x_{2}, x_{3}\right)\right)
$$

and so, from (4.5), we deduce that

$$
d\left(x_{3}, x_{4}\right)<q_{2} H\left(T x_{2}, T x_{3}\right) \leq q_{2} \psi\left(d\left(x_{2}, x_{3}\right)\right)=\psi\left(\psi\left(q \psi\left(t_{0}\right)\right)\right) .
$$

By continuing this process, we obtain a sequence $\left\{x_{n}\right\}$ in $X$ such that $x_{n} \in T x_{n-1}, x_{n} \neq x_{n-1}$, $\alpha_{*}\left(x_{n}, x_{n+1}\right) \geq \eta_{*}\left(x_{n}, x_{n+1}\right)$ and $d\left(x_{n}, x_{n+1}\right) \leq \psi^{n-1}\left(q \psi\left(t_{0}\right)\right)$ for all $n \in \mathbb{N}$. Now, for all $m>n$, we can write

$$
d\left(x_{n}, x_{m}\right) \leq \sum_{k=n}^{m-1} d\left(x_{k}, x_{k+1}\right) \leq \sum_{k=n}^{m-1} \psi^{k-1}\left(q \psi\left(t_{0}\right)\right) .
$$

Therefore, $\left\{x_{n}\right\}$ is a Cauchy sequence. Since $(X, d)$ is a complete metric space, then there exists $z \in X$ such that $x_{n} \rightarrow z$ as $n \rightarrow \infty$. Now, since $\alpha\left(x_{n}, z\right) \geq \eta\left(x_{n}, z\right)$ for all $n \in \mathbb{N}$, then $\alpha_{*}\left(T x_{n}, T z\right) \geq \eta_{*}\left(T x_{n}, T z\right)$, and so, from (4.1), we have

$$
d(z, T z) \leq H\left(T x_{n}, T z\right)+d\left(x_{n}, z\right) \leq \psi\left(d\left(x_{n}, z\right)\right)+d\left(x_{n}, z\right)
$$

for all $n \in \mathbb{N}$. Taking limit as $n \rightarrow \infty$ in the inequality above, we get $d(z, T z)=0$, i.e., $z \in T z$.

If in Theorem 4.1 we take $\eta(x, y)=1$, we have the following corollary. 
Corollary 4.1 Let $(X, d)$ be a complete metric space, and let $T: X \rightarrow 2^{X}$ be an $\alpha_{*}$ admissible and closed-valued multifunction on X. Assume that

$$
x, y \in X, \quad \alpha_{*}(T x, T y) \geq 1 \quad \Longrightarrow \quad H(T x, T y) \leq \psi(d(x, y)) .
$$

Also, suppose that the following assertions hold:

(i) there exists $x_{0} \in X$ and $x_{1} \in T x_{0}$ such that $\alpha\left(x_{0}, x_{1}\right) \geq 1$;

(ii) for a sequence $\left\{x_{n}\right\} \subset X$ converging to $x \in X$ and $\alpha\left(x_{n}, x_{n+1}\right) \geq 1$ for all $n \in \mathbb{N}$, we have $\alpha\left(x_{n}, x\right) \geq 1$ for all $n \in \mathbb{N}$.

Then $T$ has a fixed point.

If in Theorem 4.1 we take $\alpha(x, y)=1$, then we have the following result.

Corollary 4.2 Let $(X, d)$ be a complete metric space, and let $T: X \rightarrow 2^{X}$ be an $\eta_{*^{-}}$ subadmissible and closed-valued multifunction on X. Assume that

$$
x, y \in X, \quad \eta_{*}(T x, T y) \leq 1 \quad \Longrightarrow \quad H(T x, T y) \leq \psi(d(x, y)) .
$$

Also, suppose that the following assertions hold:

(i) there exists $x_{0} \in X$ and $x_{1} \in T x_{0}$ such that $\eta\left(x_{0}, x_{1}\right) \leq 1$;

(ii) for a sequence $\left\{x_{n}\right\} \subset X$ converging to $x \in X$ and $\eta\left(x_{n}, x_{n+1}\right) \leq 1$ for all $n \in \mathbb{N}$, we have $\eta\left(x_{n}, x\right) \leq 1$ for all $n \in \mathbb{N}$.

Then $T$ has a fixed point.

Corollary 4.3 (Theorem 2.1 and 2.3 of [12]) Let $(X, d)$ be a complete metric space, and let $T: X \rightarrow 2^{X}$ be an $\alpha_{*}$-admissible and closed-valued multifunction on $X$. Assume that

$$
\alpha_{*}(T x, T y) H(T x, T y) \leq \psi(d(x, y))
$$

for all $x, y \in X$. Also, suppose that the following assertions hold:

(i) there exists $x_{0} \in X$ and $x_{1} \in T x_{0}$ such that $\alpha\left(x_{0}, x_{1}\right) \geq 1$;

(ii) for a sequence $\left\{x_{n}\right\} \subset X$ converging to $x \in X$ and $\alpha\left(x_{n}, x_{n+1}\right) \geq 1$ for all $n \in \mathbb{N}$, we have $\alpha\left(x_{n}, x\right) \geq 1$ for all $n \in \mathbb{N}$.

Then $T$ has a fixed point.

Proof Suppose that $\alpha_{*}(T x, T y) \geq 1$ for $x, y \in X$. Then by (4.6), we have

$$
H(T x, T y) \leq \psi(d(x, y)) .
$$

That is, conditions of Corollary 4.1 hold, and $T$ has a fixed point.

Similarly, we can deduce the following corollaries.

Corollary 4.4 Let $(X, d)$ be a complete metric space, and let $T: X \rightarrow 2^{X}$ be an $\alpha_{*-}$ admissible and closed-valued multifunction on X. Assume that

$$
\left(\alpha_{*}(T x, T y)+1\right)^{H(T x, T y)} \leq 2^{\psi(d(x, y))}
$$


for all $x, y \in X$. Also, suppose that the following assertions hold:

(i) there exists $x_{0} \in X$ and $x_{1} \in T x_{0}$ such that $\alpha\left(x_{0}, x_{1}\right) \geq 1$;

(ii) for a sequence $\left\{x_{n}\right\} \subset X$ converging to $x \in X$ and $\alpha\left(x_{n}, x_{n+1}\right) \geq 1$ for all $n \in \mathbb{N}$, we have $\alpha\left(x_{n}, x\right) \geq 1$ for all $n \in \mathbb{N}$.

Then $T$ has a fixed point.

Corollary 4.5 Let $(X, d)$ be a complete metric space, and let $T: X \rightarrow 2^{X}$ be an $\alpha_{*}$ admissible and closed-valued multifunction on X. Assume that

$$
(H(T x, T y)+\ell)^{\alpha_{*}(T x, T y)} \leq \psi(d(x, y))+\ell
$$

for all $x, y \in X$, where $\ell>0$. Also, suppose that the following assertions hold:

(i) there exists $x_{0} \in X$ and $x_{1} \in T x_{0}$ such that $\alpha\left(x_{0}, x_{1}\right) \geq 1$;

(ii) for a sequence $\left\{x_{n}\right\} \subset X$ converging to $x \in X$ and $\alpha\left(x_{n}, x_{n+1}\right) \geq 1$ for all $n \in \mathbb{N}$, we have $\alpha\left(x_{n}, x\right) \geq 1$ for all $n \in \mathbb{N}$.

Then $T$ has a fixed point.

Corollary 4.6 Let $(X, d)$ be a complete metric space, and let $T: X \rightarrow 2^{X}$ be an $\eta_{*}$ subadmissible and closed-valued multifunction on X. Assume that

$$
H(T x, T y) \leq \eta_{*}(T x, T y) \psi(d(x, y))
$$

for all $x, y \in X$. Also, suppose that the following assertions hold:

(i) there exists $x_{0} \in X$ and $x_{1} \in T x_{0}$ such that $\eta\left(x_{0}, x_{1}\right) \leq 1$;

(ii) for a sequence $\left\{x_{n}\right\} \subset X$ converging to $x \in X$ and $\eta\left(x_{n}, x_{n+1}\right) \leq 1$ for all $n \in \mathbb{N}$, we have $\eta\left(x_{n}, x\right) \leq 1$ for all $n \in \mathbb{N}$.

Then $T$ has a fixed point.

Corollary 4.7 Let $(X, d)$ be a complete metric space, and let $T: X \rightarrow 2^{X}$ be an $\eta_{*^{-}}$ subadmissible and closed-valued multifunction on X. Assume that

$$
2^{H(T x, T y)} \leq\left(\eta_{*}(T x, T y)+1\right)^{\psi(d(x, y))}
$$

for all $x, y \in X$. Also, suppose that the following assertions hold:

(i) there exists $x_{0} \in X$ and $x_{1} \in T x_{0}$ such that $\eta\left(x_{0}, x_{1}\right) \leq 1$;

(ii) for a sequence $\left\{x_{n}\right\} \subset X$ converging to $x \in X$ and $\eta\left(x_{n}, x_{n+1}\right) \leq 1$ for all $n \in \mathbb{N}$, we have $\eta\left(x_{n}, x\right) \leq 1$ for all $n \in \mathbb{N}$.

Then $T$ has a fixed point.

Corollary 4.8 Let $(X, d)$ be a complete metric space, and let $T: X \rightarrow 2^{X}$ be an $\alpha_{*}$ admissible and closed-valued multifunction on X. Assume that

$$
H(T x, T y)+\ell \leq(\psi(d(x, y))+\ell)^{\eta_{*}(T x, T y)}
$$

for all $x, y \in X$, where $\ell>0$. Also, suppose that the following assertions hold:

(i) there exists $x_{0} \in X$ and $x_{1} \in T x_{0}$ such that $\eta\left(x_{0}, x_{1}\right) \leq 1$; 
(ii) for a sequence $\left\{x_{n}\right\} \subset X$ converging to $x \in X$ and $\eta\left(x_{n}, x_{n+1}\right) \leq 1$ for all $n \in \mathbb{N}$, we have $\eta\left(x_{n}, x\right) \leq 1$ for all $n \in \mathbb{N}$.

Then $T$ has a fixed point.

\section{Competing interests}

The authors declare that they have no competing interests.

Authors' contributions

All authors contributed equally and significantly in writing this article. All authors read and approved the final manuscript.

\section{Author details}

${ }^{1}$ Department of Mathematics, King Abdulaziz University, P.O. Box 80203, Jeddah, 21589, Saudi Arabia. ${ }^{2}$ Young Researchers and Elite Club, Rasht Branch, Islamic Azad University, Rasht, Iran.

\section{Acknowledgements}

This article was funded by the Deanship of Scientific Research (DSR), King Abdulaziz University, Jeddah. Therefore, the first and third authors acknowledge with thanks DSR, KAU for the financial support.

Received: 21 May 2013 Accepted: 23 July 2013 Published: 8 August 2013

\section{References}

1. Akbar, F, Khan, AR: Common fixed point and approximation results for noncommuting maps on locally convex spaces. Fixed Point Theory Appl. 2009, Article ID 207503 (2009)

2. Ćirić, L, Hussain, N, Cakic, N: Common fixed points for Ćirić type $f$-weak contraction with applications. Publ. Math. (Debr.) 76(1-2), 31-49 (2010)

3. Ćirić, L, Abbas, M, Saadati, R, Hussain, N: Common fixed points of almost generalized contractive mappings in ordered metric spaces. Appl. Math. Comput. 217, 5784-5789 (2011)

4. Geraghty, MA: On contractive mappings. Proc. Am. Math. Soc. 40, 604-608 (1973)

5. Hussain, N, Berinde, V, Shafqat, N: Common fixed point and approximation results for generalized $\phi$-contractions. Fixed Point Theory 10, 111-124 (2009)

6. Hussain, N, Khamsi, MA, Latif, A: Common fixed points for $\mathrm{JH}$-operators and occasionally weakly biased pairs under relaxed conditions. Nonlinear Anal. 74, 2133-2140 (2011)

7. Hussain, N, Kadelburg, Z, Radenovic, S, Al-Solamy, FR: Comparison functions and fixed point results in partial metric spaces. Abstr. Appl. Anal. 2012, Article ID 605781 (2012)

8. Hussain, N, Djorić, D, Kadelburg, Z, Radenović, S: Suzuki-type fixed point results in metric type spaces. Fixed Point Theory Appl. 2012, Article ID 126 (2012)

9. Hussain, N, Karapinar, E, Salimi, P, Akbar, F: $\alpha$-admissible mappings and related fixed point theorems. J. Inequal. Appl. 2013, Article ID 114 (2013)

10. Hussain, N, Karapinar, E, Salimi, P, Vetro, P: Fixed point results for $G^{m}$-Meir-Keeler contractive and G- $(\alpha, \psi)-$ Meir-Keeler contractive mappings. Fixed Point Theory Appl. 2013, Article ID 34 (2013)

11. Karapinar, E, Kumam, P, Salimi, P: On $\alpha$ - $\psi$-Meir-Keeler contractive mappings. Fixed Point Theory Appl. 2013, Article ID 34 (2013)

12. Asl, JH, Rezapour, S, Shahzad, N: On fixed point of $\alpha$-contractive multifunctions. Fixed Point Theory Appl. 2012 Article ID 212 (2012)

13. Karapinar, E, Samet, B: Generalized $\alpha-\psi$ contractive type mappings and related fixed point theorems with applications. Abstr. Appl. Anal. 2012, Article ID 793486 (2012)

14. Salimi, P, Latif, A, Hussain, N: Modified $\alpha-\psi$-contractive mappings with applications. Fixed Point Theory Appl. 2013 Article ID 151 (2013)

15. Samet, B, Vetro, C, Vetro, P: Fixed point theorem for $\alpha-\psi$ contractive type mappings. Nonlinear Anal. 75, 2154-2165 (2012)

16. Kadelburg, Z, Radenović, S: Meir-Keeler-type conditions in abstract metric spaces. Appl. Math. Lett. 24(8), 1411-1414 (2011)

17. Suzuki, T: A generalized Banach contraction principle that characterizes metric completeness. Proc. Am. Math. Soc. $136,1861-1869(2008)$

18. Takahashi, W, Itoh, S: The common fixed point theory of singlevalued mappings and multivalued mappings. Pac. J. Math. 79(2), 493-508 (1978)

19. Takahashi, W, Shimizu, T: Fixed points of multivalued mappings in certain convex metric spaces. Topol. Methods Nonlinear Anal. 8(1), 197-203 (1996)

20. Takahashi, W, Lin, L-J, Wang, SY: Fixed point theorems for contractively generalized hybrid mappings in complete metric spaces. J. Nonlinear Convex Anal. 13(2), 195-206 (2012)

21. Azam, A, Arshad, M: Fixed points of a sequence of locally contractive multivalued maps. Comput. Math. Appl. 57, 96-100 (2009)

doi:10.1186/1687-1812-2013-212

Cite this article as: Hussain et al.: Fixed point results for single and set-valued $\alpha-\eta-\psi$-contractive mappings. Fixed Point Theory and Applications 2013 2013:212. 